\title{
Eucommia Ulmoides Flavones as Antibiotic Alternatives in a Low-protein Diet Improve Growth Performance and Intestinal Health in Weaning Piglets
}

\section{Daixiu Yuan}

Jishou University

Jing Wang ( $\sim$ jingwang023@gmail.com )

Hunan Normal University https://orcid.org/0000-0001-8299-0359

\section{Dingfu Xiao}

Hunan Agriculture University

Jiefeng Li

Institute of Subtropical Agriculture Chinese Academy of Sciences

Yanhong Liu

University of California Davis

Bie Tan

Hunan Agriculture University

\section{Research}

Keywords: Eucommia ulmoids flavones, antibiotic alternatives, growth performance, intestinal barrier, weaning piglets

Posted Date: April 21st, 2020

DOI: https://doi.org/10.21203/rs.3.rs-22242/v1

License: (a) (i) This work is licensed under a Creative Commons Attribution 4.0 International License. Read Full License 


\section{Abstract \\ Background}

Eucommia ulmoides flavones (EUF), have been demonstrated to attenuate the inflammation and oxidative stress of piglets. This study was designed to test whether EUF could be as an antibiotic alternative to support growth performance and maintain intestinal health in weanling-piglets. Weanedpiglets $(n=480)$ were assigned into 3 groups and fed with a low-protein basal diet $(N C)$, or supplementation with antibiotics (PC) or $0.1 \%$ EUF (EUF). Blood, intestinal contents and intestine were collected on $\mathrm{d}-15$ and $\mathrm{d}-35$, respectively.

\section{Results}

The results showed that the body weight on $d-35$, average daily gain and gain : feed from $d 15$ to $d 35$ and $\mathrm{d} 0$ to $\mathrm{d} 35$ in piglets of PC and EUF treatments were higher than $(p<0.05)$ these in NC treatment, whereas PC and EUF treatments decreased $(p<0.05)$ the diarrhea index of weanling piglets. Dietary supplementation of EUF significantly enhanced $(p<0.05)$ the serum concentrations of total protein, alanine transaminase and the immunoglobulin $\mathrm{G}$ on $\mathrm{d}-15$ of piglets compared to piglets in NC treatment. EUF supplementation increased $(p<0.05)$ the jejunal and ileal villus height and the population of ileal lactic acid bacteria on $\mathrm{d}-15$ but remarkable decreased $(p<0.05)$ the population of ileal coliform bacteria on $\mathrm{d}-15$ and $\mathrm{d}-35$.

\section{Conclusion}

These findings indicated the antibiotic alternative capacity of EUF in piglets exhibiting by improving growth performance and intestinal morphology, decreasing colonization of coliform bacteria and diarrhea index in weanling piglets.

\section{Background}

Announcement No. 194 of the Ministry of Agriculture and Rural Affairs of the People's Republic of China stipulate that medicated feed additives will be prohibited for using in animal feed in 2020 [1]. Antibiotics free diets have become a necessity in livestock and poultry industry. The withdrawal of antibiotic use will lead to lower quality and yield of animals or death, more serious disease outbreaks, then result in greater use of antibiotics for therapeutic purposes [2]. Therefore, new antibiotic alternative strategies are needed to guarantee animal health and yield growth. It has been well documented that some antibiotic alternatives and feed additives, such as plant extracts, organic acids, microecologics, antimicrobial peptides, could promote the animal development and enhance the intestinal health [3-6]. 
Of the various alternative, plant extract is one of the most readily available and safe choice that being investigated [7, 8]. The Eucommia ulmoides flavones (EUF), which are bioactive phytochemicals derived from the leaves of Eucommia ulmoides, have been demonstrated to improve the antioxidative function by reacting with free radicals [9], inhibit the growth of bacteria and reduce the response of inflammation in previous studies [10-12]. Our group has showed that EUF alleviate the oxidative stress induced by diquat in piglets by reducing the growth performance impairment, pro-inflammatory cytokines secretion and intestinal barrier dysfunction [3, 13]. Meanwhile, we recently reported the NF-E2-related factor 2 (Nrf2) signaling pathway played an important role in EUF-regulating oxidative stress in the intestine of piglets [14]. The Nrf2 pathway not only involved in antioxidant by regulating the mRNA levels of antioxidant enzymes, but also enhancing the intestinal barrier integrity through increasing the expression of tight junction proteins [15]. The improved functional gut immunity and integrity were vital to reduce the permeability for viable pathogens and pathogen colonization in the gut. These benefit effects may enable it to be an effective antibiotic alternative to promote animal growth in animal husbandry.

Therefore, the present study was conducted to investigate the effect of EUF as antibiotic alternative in a low-protein diet on growth performance and intestinal health of weaning piglets. The low-protein diet was used in this study because it was benefit to relieve the nutritional burden of excess dietary protein and alleviate intestinal dysfunction and diseases [16]. Growth performance, serum biochemical parameters, intestinal morphology and microbiota composition were monitored so as to provide the scientific basis for the application of EUF in antibiotics-free diets in swine production.

\section{Methods}

The animal experiments were approved by the Institutional Animal Care and Use Committee of Hunan Agricultural University, Hunan, China.

\section{Animal Protocol and Dietary Treatment}

A total of 480 piglets (Duroc $\times$ Landrace $\times$ Large Yorkshire) weaned at 25-d of age were randomly assigned to 3 groups (8 pens per group and 20 piglets per pen) as follows: (1) Negative Control (NC), lowprotein basal diet no antibiotics included; (2) Positive control (PC), low-protein Basal diet + antibiotics (75 ppm quinocetone, 20 ppm virginomycin and 50 ppm aureomycin); (3) EUF treatment (EUF), low-protein Basal diet $+0.1 \%$ o EUF. The low-protein basal diet was formulated in two phases (phase 1, days 0-15; phase 2, days 15-35) according to the nutrient requirements for weanling piglets (NRC, 2012) and the previous studies [17] (Table 1). EUF powder contained $83.61 \%$ total flavones was prepared at the department of medicine, Jishou University (Jishou, Hunan, China), which has been used in the previous study by Yuan et al [13]. Additives were added to the negative control diet at the expense of corn.

The piglets were housed in an environmentally controlled nursery with hard plastic slatted flooring, and had free access to drinking water. Piglets were fed their respective diets 3 times per day at 8:00, 13:00 and 18:00 for a 35-d period. On the morning at $d 15$ and 35, 24 piglets (1 piglet per pen) were randomly selected and blood samples were obtained aseptically from the jugular vein at $2 \mathrm{~h}$ after feeding. Serum 
samples were obtained by centrifugation at $2000 \times g$ for $10 \mathrm{~min}$ at $4{ }^{\circ} \mathrm{C}$ and then immediately stored at $-80^{\circ} \mathrm{C}$ for further analysis. Piglets were anesthetized with sodium pentobarbital and killed by jugular puncture. And the intestine samples were collected after rinsing thoroughly with ice-cold physiological saline solution. About $2 \mathrm{~cm}$ segments of the jejunum and ileum were cut and fixed in $4 \%$ formaldehyde for observation of the morphology of intestinal mucosa. Ileal and colonic contents were collected for bacteria counting and DNA extraction.

\section{Growth Performance, Diarrhea Index}

Body weight and feed intake were measured at day 15 and 35 . Average daily gain, average daily feed intake and gain : feed ratio were calculated. The number of pigs with diarrhea was recorded every day. Diarrhea index (\%) was calculated as the number of diarrhea piglets $\times$ diarrhea days / the total number of piglets $\times$ experiment days.

\section{Intestinal Morphology Evaluation}

The jejunal and ileal morphology were analyzed using hemotoxylin eosin staining according to Xiao et al. [18]. Villous height and crypt depth were measured with computer-assisted microscopy (Micrometrics TM; Nikon ECLIPSE E200, Tokyo, Japan).

\section{Serum Biochemical Parameters Determination}

Total protein (TP), Albumin (ALB), blood urea nitrogen (BUN), glucose (GLU), alanine aminotransferase (ALT), aspartate aminotransferase (AST), alkaline phosphatase (ALP), immunoglobulin G (IgG) and IgM in the serum were measured using Biochemical Analytical Instrument (Cobas c311, F. Hoffmann-La Roche Ltd., Basel, Switzerland) and commercial kits (F. Hoffmann-La Roche Ltd., Basel, Switzerland).

\section{Microbiota Composition Analysis}

Bacteria counting were performed according to the previous studies $[5,19] .0 .2 \mathrm{~g}$ of ileal and colonic contents were collected and immediately diluted with $9 \mathrm{~mL}$ of $0.9 \%$ sterilizing saline and homogenized. Then, 10 -fold dilutions of homogenate were performed (ranging from $10^{-1}$ to $10^{-8}$ ) and then cultivated onto MacConkey Agar Medium for the enumeration of Escherichia coli, and GM17 Medium for the enumeration of Lactic acid bacteria. The GM17 medium were then incubated for $48 \mathrm{~h}$ at $30^{\circ} \mathrm{C}$ under anaerobic conditions, while the MacConkey agar plates were incubated for $24 \mathrm{~h}$ at $37^{\circ} \mathrm{C}$. The coliform bacteria and lactic acid bacteria colonies were counted immediately after removal from the incubator. Values were reported as log10 colony-forming units per gram.

DNA was extracted from ileul and colonic contents with the Tiangen stool mini kit (TianGen) according to the instructions of the manufacturer. DNA concentration was determined by spectrophotometry (Nanodrop). The DNA obtained from the intestinal luminal content was used as the template to analyze intestinal bacteria by qRT-PCR. Primers (Lactobacillus spp. (F) 5'-CACCGCTACACATGGAG-3' (R) 5'TGGAAGATTCCCTACTGCT-3', Escherichia coli (F) 5'-CATGCCGCGTGTATGAAGAA-3' (R) 5'- 
TTTGCTCATTGACGTTACCCG-3', total bacteria (F) 5'-ACTCCTACGGGAGGCAGCAG-3' (R) 5'-

ATTACCGCGGCTGCTGG-3') were synthesized according to the previous study [20]. Relative expression of genes in the treatment group was normalized to the values for the NC.

\section{Statistical Analysis}

All data were subjected to ANOVA analysis using SPSS 17.0 software (SPSS, Inc., Chicago, IL, USA). The differences among treatments were evaluated using Tukey's test. Probability values $p<0.05$ were taken to indicate statistical significance.

\section{Results}

\section{Growth Performance and Diarrhea Index}

The average daily gain, average daily feed intake, and gain : feed were showed in Figure 1 . The body weight on $\mathrm{d} 0$ and 15 were not different among all treatments $(p>0.05)$. The body weight of piglets in PC and EUF treatments were less $(p<0.05)$ than those in the NC treatment on $\mathrm{d} 35$. Compared with the piglets of NC treatment, PC and EUF treatments increased average daily gain and gain:feed from $\mathrm{d} 15$ to 35 and $d 0$ to $35(p<0.05)$. However, there was no difference in average daily feed intake of all experimental periods among all treatments $(p>0.05)$. The diarrhea index in the piglets of PC and EUF treatments from $\mathrm{d} 0$ to 15 and $\mathrm{d} 0$ to 35 were significantly lower than those of NC treatment $(p<0.05)$ (Figure 2).

\section{Serum Biochemical Parameters}

Dietary supplementation with EUF increased $(p<0.05)$ the serum concentrations of TP and IgG, as well as ALT activity on d 15 and serum TP content on d 35 compared to NC treatment. But in comparison to PC treatment, EUF addition only promoted $(p<0.05)$ serum TP content and ALP activity on $\mathrm{d} 15$ and there was no difference $(p>0.05)$ in other determined serum biochemical parameters on d 15 or 35 (Table 2).

\section{Microbiota Composition in lleum and Colon}

In the ileum, EUF addition increased the number of Lactic acid bacteria on $\mathrm{d} 15$ but decreased the number of Coliform bacteria on $\mathrm{d} 15$ and 35 compared with NC treatment $(p<0.05)$. And no significant difference was observed in the numbers of Lactic acid bacteria and Coliform bacteriabetween PC and EUF treatments on $\mathrm{d} 15$ and $35(p>0.05)$ (Table 3$)$. For the relative abundance of selected microbiota, both PC and EUF treatments significantly decreased the population of Escherichia coli on d 15 and 35 but increased the population of Lactobacillus spp. on d 15 in the ileum compared to those of NC treatment ( $p$ $<0.05$ ) (Figure 3). There was no difference in determined microbiota in the colon among three treatments on $\mathrm{d} 15$ and $35(p>0.05)$.

\section{Intestinal Morphology}


Dietary supplementation with EUF increased $(p<0.05)$ the jejunal and ileal villus height on $\mathrm{d} 15$ compared to these in NC treatment. No difference was observed on villus height and crypt depth in jejunum and ileum between PC and EUF treatments on d 15 and $35(p>0.05)$ (Table 4).

\section{Discussion}

The present study demonstrated that dietary supplementation with EUF in a low-protein and antibioticfree diet improved growth performance and intestinal morphology, decreased the colonization of coliform bacteria and diarrhea index in weaning piglets. A low-protein diet was used as basal diet, which could improve intestinal health. Growing evidences have showed that feeding a low-protein in post-weaning period decreased the cost of feed while effectively relieving the nutritional burden of excess dietary protein by decreasing hindgut microbial protein fermentation [16, 21]. Although reducing the dietary protein content and removing antibiotics influence the growth performance and intestinal microbial structure [22, 23], the low-protein diets is an efficient way for antibiotic alternative.

Ideal antibiotic alternatives should have the same beneficial effects of antibiotic growth promoters, ensuring optimum animal performance and nutrient availability [8]. Similar increases in body weight, average daily gain and feed efficacy between the piglets of antibiotic positive control and EUF treatment were obtained in our present study. In addition, EUF supplementation promoted serum TP content and ALP activity, which in a certain extent showing the increased nutrient efficiency [24]. It is important to develop an alternative strategy to stimulate innate immune response and limit the infections in livestock, and subsequently decrease the use of antibiotics $[25,26]$. IgG is a feature of immune cell maturation and plays a critical role in defensing against infection via the direct neutralization of toxins and microbes [27-29]. Dietary supplementation with EUF was shown to enhance the serum IgG concentration in current study. Results from our previous published report also demonstrated that EUF exerts immunomodulatory activities by modifying the production of cytokines in vivo [13] and regulating the NF-KB pathway in vitro [30].

The proposed mechanism of promoting growth effects of a practical alternative may be involved in modulating the gut microbiome $[7,8,31]$. Weaning stress induces the population of pathogenic Escherichia coli to proliferate to exceed those of other bacterial populations, which is associated with many diseases after weaning [32]. Removing antibiotics from the diet will inevitably lead to a further increase in the number of microorganisms [33]. In current study, antibiotic free dietary supplementation with EUF significantly increased the population of lactic acid bacteria and decreased coliform bacteria in ileal content. Various stress factors exposed to piglets could lead to microbial imbalance due to the increased Enterobacteriaceae and decreased lactic acid bacteria counts resulting in infectious diarrhea $[34,35]$. Lactic acid bacteria is most commonly used probiotic in livestock, and predominant at the early stage of pig gut microflora construction [36]. Increased lactic acid bacteria can reduce fecal pH and ammonia nitrogen levels [34,37], as well as prevent colonization of pathogenic organism colonization, 
therefore improve the natural microbiome and gut health [31]. Lots of bioactive antimicrobial chemical forms, including phenolic acids, quinones, flavonoids, tannins and alkaloids, have been identified and been used in animal nutrition $[7,8]$. However, due to their complex compositions and the potential for multiple sites of action, the mechanisms of antibacterial activity are not fully understood. One of the mechanisms of inhibitory action is involved that hydroxyl groups in phenolic compounds interact with the cell membrane of bacteria to disrupt membrane structures and cause the leakage of cellular components [38].

Recent studies have explored that antibiotic exposure early in life has long-term consequences on intestinal homeostasis and epithelial barrier function [39, 40]. In addition to antibacterial activity, the effect of EUF on the intestinal barrier function was investigated in present study. Although we did not detect the tight junction protein expression and intestinal permeability, the significantly increased villus height in jejunal and ileal mucosa were observed in EUF supplemented group. In our previous study, EUF improved the morphology structure and barrier function of intestine in piglets challenged by diquat exhibiting higher intestinal villus height and lower serum concentrations of D-lactate and diamine oxidase [13]. The intestinal barrier is the first line of defense against pathogen attachment to and invasion of epithelial cells [41]. The effect of EUF on intestinal barrier function may benefit its ability to enhance host defense against microbial infections $[8,42]$.

\section{Conclusion}

In summary, flavones extracted from Eucommia ulmoides leaf have shown the health-promoting properties and antibiotic alternative capacities in weanling piglets fed a low-protein diet. The results indicated that EUF improved the growth performance, maintained the intestinal barrier morphology, enhanced the serum immunoglobulin $\mathrm{G}$ level, as well as reduced the colonization of coliform bacteria and diarrhea index in weaning piglets. These findings can contribute to exploration of EUF as a potential alternative antibiotic to against the microbe infection in swine production although further studies are needed to further explain the mechanism.

\section{Abbreviations}

EUF: Eucommia ulmoides flavones; NC: basal diet; PC: diet supplementation with antibiotics; Nrf2: NF-E2related factor 2; TP: total protein; ALB: Albumin; BUN: blood urea nitrogen; GLU: glucose; ALT: alanine aminotransferase; AST: aspartate aminotransferase; ALP: alkaline phosphatase; IgG: immunoglobulin G.

\section{Declarations}

\section{Acknowledgments}

We thank the many undergraduate students who aided in the collection of samples for this study as well as the staff at the Hunan Agricultural University Animal Sciences Teaching, Research, and Education 
Complex. We thank the Institute of Subtropical Agriculture and Hunan Normal University Life Science for support

\section{Funding}

This project was funded by the National Natural Science Foundation of China (31960666, 31872991), Key Project of Hunan Provincial Education Department (16A096), Open Fund of National \& Local United Engineering Laboratory of Integrative Utilization Technology of Eucommia Ulmoides (NLE201703) and China Postdoctoral Science Foundation (BX20180096).

\section{Availability of data and materials}

The datasets supporting the conclusions of this article are included within the article.

\section{Author contributions}

Conceptualization, J.W., X.D. and B.T.; Methodology, X.D. and D.Y.; Formal Analysis, D.Y. and J.L; Data Curation, D.Y. and J.L.; Writing - Original Draft Preparation, D.Y.; Writing - Review \& Editing, J.W. and Y.L.; Supervision, X.D. and B.T.

\section{Ethics approval and consent to participate}

The authors confirm that the ethical policies of the journal, as noted on the journal's author guidelines page, have been adhered to and the appropriate ethical review committee approval has been received. The authors confirm that they have followed standards for the protection of animals used for scientific purposes. All animal experimental procedures were approved by the Institutional Animal Care and Use Committee of Hunan Agricultural University, Hunan, China.

\section{Consent for publication}

Not applicable.

\section{Competing interests}

The authors declare that they have no competing interests.

\section{References}

1. Wang JY, Johnson LR. Expression of protooncogenes c-fos and c-myc in healing of gastric mucosal stress ulcers. American Journal of Physiology-Gastrointestinal Liver Physiology. 1994;266(5):G87886.

2. Ma YH. Formulation and Evaluation of Multi-particulate Antibiotic Alternatives for Oral Delivery to Livestock Animals to Target Gut Pathogens.PhD diss. 2016. 
3. Zou Y, Xiang Q, Wang J, Peng J, Wei H. Oregano essential oil improves intestinal morphology and expression of tight junction proteins associated with modulation of selected intestinal bacteria and immune status in a pig model. BioMed research international. 2016;2016.

4. Long S, Xu Y, Pan L, Wang Q, Wang C, Wu J, et al. Mixed organic acids as antibiotic substitutes improve performance, serum immunity, intestinal morphology and microbiota for weaned piglets. Anim Feed Sci Technol. 2018;235:23-32.

5. Li S, Zheng J, Deng K, Chen L, Zhao XL, Jiang X, et al. Supplementation with organic acids showing different effects on growth performance, gut morphology, and microbiota of weaned pigs fed with highly or less digestible diets. J Anim Feed Sci. 2018;96(8):3302-18.

6. Dowarah R, Verma A, Agarwal N. The use of Lactobacillus as an alternative of antibiotic growth promoters in pigs: A review. Animal Nutrition. 2017;3(1):1-6.

7. Omonijo FA, Ni L, Gong J, Wang Q, Lahaye L, Yang C. Essential oils as alternatives to antibiotics in swine production. Animal Nutrition. 2018;4(2):126-36.

8. Lillehoj H, Liu Y, Calsamiglia S, Fernandez-Miyakawa ME, Chi F, Cravens RL, et al. Phytochemicals as antibiotic alternatives to promote growth and enhance host health. Vet Res. 2018;49(1):76.

9. Park SA, Choi M-S, Jung UJ, Kim M-J, Kim DJ, Park H-M, et al. Eucommia ulmoides Oliver leaf extract increases endogenous antioxidant activity in type 2 diabetic mice. J Med Food. 2006;9(4):474-9.

10. Zhang L, Ravipati AS, Koyyalamudi SR, Jeong SC, Reddy N, Smith PT, et al. Antioxidant and antiinflammatory activities of selected medicinal plants containing phenolic and flavonoid compounds. J Agr Food Chem. 2011;59(23):12361-7.

11. Zhang L, Ravipati AS, Koyyalamudi SR, Jeong SC, Reddy N, Bartlett J, et al. Anti-fungal and antibacterial activities of ethanol extracts of selected traditional Chinese medicinal herbs. Asian Pac $J$ Trop Med. 2013;6(9):673-81.

12. Kim BH, Park KS, Chang IM. Elucidation of anti-inflammatory potencies of Eucommia ulmoides bark and Plantago asiatica seeds. J Med Food. 2009;12(4):764-9.

13. Yuan D, Hussain T, Tan B, Liu Y, Ji P, Yin Y. The evaluation of antioxidant and anti-inflammatory effects of Eucommia ulmoides flavones using diquat-challenged piglet models. Oxid Med Cell Longev. 2017;2017.

14. Xiao D, Yuan D, Tan B, Wang J, Liu Y, Tan B. The Role of Nrf2 Signaling Pathway in Eucommia ulmoides Flavones Regulating Oxidative Stress in the Intestine of Piglets. Oxid Med Cell Longev. 2019;2019.

15. Singh R, Chandrashekharappa S, Bodduluri SR, Baby BV, Hegde B, Kotla NG, et al. Enhancement of the gut barrier integrity by a microbial metabolite through the Nrf2 pathway. Nat Commun. 2019;10(1):1-18.

16. Zhou J, Wang Y, Zeng X, Zhang T, Li P, Yao B, et al. Effect of antibiotic-free, low-protein diets with specific amino acid compositions on growth and intestinal flora in weaned pigs. Food Funct. 2020.

17. Yin J, Li Y, Zhu X, Han H, Ren W, Chen S, et al. Effects of long-term protein restriction on meat quality, muscle amino acids, and amino acid transporters in pigs. J Agr Food Chem. 2017;65(42):9297-304. 
18. Xiao H, Tan B, Wu M, Yin Y, Li T, Yuan D, et al. Effects of composite antimicrobial peptides in weanling piglets challenged with deoxynivalenol: II. Intestinal morphology and function. J Anim Sci. 2013;91(10):4750-6.

19. Ren W, Liu S, Chen S, Zhang F, Li N, Yin J, et al. Dietary L-glutamine supplementation increases Pasteurella multocida burden and the expression of its major virulence factors in mice. Amino Acids. 2013;45(4):947-55.

20. Castillo M, Martín-Orúe SM, Manzanilla EG, Badiola I, Martín M, Gasa J. Quantification of total bacteria, enterobacteria and lactobacilli populations in pig digesta by real-time PCR. Vet Microbiol. 2006;114(1-2):165-70.

21. Rist V, Weiss E, Eklund M, Mosenthin R. Impact of dietary protein on microbiota composition and activity in the gastrointestinal tract of piglets in relation to gut health: a review. Animal. 2013;7(7):1067-78.

22. Wu Y, Jiang Z, Zheng C, Wang L, Zhu C, Yang X, et al. Effects of protein sources and levels in antibiotic-free diets on diarrhea, intestinal morphology, and expression of tight junctions in weaned piglets. Animal Nutrition. 2015;1(3):170-6.

23. Rettedal E, Vilain S, Lindblom S, Lehnert K, Scofield C, George S, et al. Alteration of the ileal microbiota of weanling piglets by the growth-promoting antibiotic chlortetracycline. Appl Environ Microbiol. 2009;75(17):5489-95.

24. Wu X, Liu Z, Zhang T, Yang Y, Yang F, Gao X. Effects of dietary copper on nutrient digestibility, tissular copper deposition and fur quality of growing-furring mink (Mustela vison). Biol Trace Elem Res. 2014;158(2):166-75.

25. Gadde U, Oh S, Lee Y, Davis E, Zimmerman N, Rehberger T, et al. The effects of direct-fed microbial supplementation, as an alternative to antibiotics, on growth performance, intestinal immune status, and epithelial barrier gene expression in broiler chickens. Probiotics Antimicro. 2017;9(4):397-405.

26. Bussy F, Salmon H, Delaval J, Berri M, Pi NC. Immunomodulating effect of a seaweed extract from Ulva armoricana in pig: Specific IgG and total IgA in colostrum, milk, and blood. Turk J Vet Anim Sci. 2019;7:100051.

27. Ohsaki A, Venturelli N, Buccigrosso TM, Osganian SK, Lee J, Blumberg RS, et al. Maternal IgG immune complexes induce food allergen-specific tolerance in offspring. J Exp Med. 2018;215(1):91-113.

28. Noris M, Remuzzi G. Overview of complement activation and regulation. In: Seminars in nephrology: 2013. Elsevier: 479-492.

29. de Agüero MG, Ganal-Vonarburg SC, Fuhrer T, Rupp S, Uchimura Y, Li H, et al. The maternal microbiota drives early postnatal innate immune development. Science. 2016;351(6279):1296-302.

30. Hussain T, Yuan D, Tan B, Murtaza G, Rahu N, Kalhoro MS, et al. Eucommia ulmoides flavones (EUF) abrogated enterocyte damage induced by LPS involved in NF-KB signaling pathway. Toxicol In Vitro. 2020;62:104674. 
31. Wang J, Han M, Zhang G, Qiao S, Li D, Ma X. The signal pathway of antibiotic alternatives on intestinal microbiota and immune function. Curr Protein Pept Sc. 2016;17(8):785-96.

32. Wang S, Blachier F, Zhao F, Yin Y. Intestinal microbiota: Development, metabolism and functions. J Food Agric Environ. 2011;9:121-9.

33. Walsh M, Sholly D, Hinson R, Saddoris K, Sutton A, Radcliffe J, et al. Effects of water and diet acidification with and without antibiotics on weanling pig growth and microbial shedding. J Anim Sci. 2007;85(7):1799-808.

34. Thu T, Loh TC, Foo H, Yaakub H, Bejo M. Effects of liquid metabolite combinations produced by Lactobacillus plantarum on growth performance, faeces characteristics, intestinal morphology and diarrhoea incidence in postweaning piglets. Trop Anim Health Pro. 2011;43(1):69-75.

35. Taras D, Vahjen W, Macha M, Simon O. Performance, diarrhea incidence, and occurrence of Escherichia coli virulence genes during long-term administration of a probiotic Enterococcus faecium strain to sows and piglets. J ANIM SCI. 2006;84(3):608-17.

36. Yeo S, Lee S, Park H, Shin H, Holzapfel W, Huh CS. Development of putative probiotics as feed additives: validation in a porcine-specific gastrointestinal tract model. Appl Microbiol Biot. 2016;100(23):10043-54.

37. García KE, de Souza TCR, Landín GM, Barreyro AA, Santos MGB, Soto JGG. Microbial fermentation patterns, diarrhea incidence, and performance in weaned piglets fed a low protein diet supplemented with probiotics. Pol J Food Nutr Sci. 2014;5(18):1776.

38. Lai P, Roy J. Antimicrobial and chemopreventive properties of herbs and spices. Curr Med Chem. 2004;11(11):1451-60.

39. Rabanal F, Grau-Campistany A, Vila-Farrés X, Gonzalez-Linares J, Borràs M, Vila J, et al. A bioinspired peptide scaffold with high antibiotic activity and low in vivo toxicity. Sci Rep-Uk. 2015;5:10558.

40. Cho I, Yamanishi S, Cox L, Methé BA, Zavadil J, Li K, et al. Antibiotics in early life alter the murine colonic microbiome and adiposity. Nature. 2012;488(7413):621-6.

41. Farhadi A, Banan A, Fields J, Keshavarzian A. Intestinal barrier: an interface between health and disease. J Gastroen Hepatol. 2003;18(5):479-97.

42. Lillehoj HS, Kim DK, Bravo DM, Lee SH. Effects of dietary plant-derived phytonutrients on the genome-wide profiles and coccidiosis resistance in the broiler chickens. In: BMC proceedings: 2011. BioMed Central: S34.

\section{Tables}

Table1.Composition of Basal Diets (as-fed basis) 


\begin{tabular}{|c|c|c|c|c|c|}
\hline ingredients, \% & phase 1 & phase 2 & chemical composition & phase 1 & phase 2 \\
\hline corn & 57 & 60 & crude protein & 17.4 & 16.3 \\
\hline expended maize & 5 & 5 & calculated DE, $\mathrm{kcal} / \mathrm{kg}$ & 3466 & 3420 \\
\hline soybean meal (43\%CP) & 22 & 22 & & & \\
\hline rice bran meal & 5 & 5 & & & \\
\hline broken rice & 5 & 5 & & & \\
\hline fish meal & 2 & l & & & \\
\hline sucrose & 1 & l & & & \\
\hline calcium lactate & 0.3 & 0.3 & & & \\
\hline calcium hydrogen phosphate & 1 & 1 & & & \\
\hline limestone powder & 0.1 & 0.1 & & & \\
\hline premix $^{\mathrm{a}}$ & 1 & 1 & & & \\
\hline 98\% lysine & 0.4 & 0.4 & & & \\
\hline threonine & 0.1 & 0.1 & & & \\
\hline methionine & 0.1 & 0.1 & & & \\
\hline
\end{tabular}

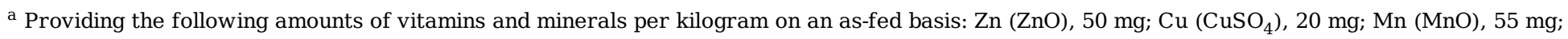

Fe (FeSO 4$), 100$ mg; I (KI), 1 mg; Co $\left(\mathrm{CoSO}_{4}\right), 2$ mg; Se $\left(\mathrm{Na}_{2} \mathrm{SeO}_{3}\right), 0.3$ mg; vitamin A, 8,255 IU; vitamin D3, 2,000 IU; vitamin E, 40 IU; vitamin B1, 2 mg; vitamin B2, 4 mg; pantothenic acid, 15 mg; vitamin B6, 10 mg; vitamin B12, 0.05 mg; nicotinic acid, 30 mg; folic acid, 2 mg; vitamin K3, 1.5 mg; biotin, $0.2 \mathrm{mg}$; choline chloride, $800 \mathrm{mg}$; and vitamin C, $100 \mathrm{mg}$. The premix did not contain additional copper, zinc, antibiotics, or probiotics.

Table2. Serum biochemical parameters of piglets 


\begin{tabular}{|c|c|c|c|c|c|}
\hline Items & NC & PC & EUF & SEM & $P$-valve \\
\hline \multicolumn{6}{|l|}{ Day 15} \\
\hline Total protein, $\mathrm{g} / \mathrm{L}$ & $48.29^{b}$ & $50.21^{b}$ & $59.82^{\mathrm{a}}$ & 2.30 & 0.006 \\
\hline Albumin, $g / L$ & 32.15 & 35.94 & 37.45 & 3.04 & 0.552 \\
\hline Blood urea nitrogen, $\mathrm{mmol} / \mathrm{L}$ & 4.21 & 4.53 & 4.78 & 0.16 & 0.075 \\
\hline Glucose, mmol/L & 6.78 & 6.49 & 6.53 & 0.20 & 0.629 \\
\hline Alanine transaminase, U/L & $32.38^{\mathrm{b}}$ & $38.59^{\mathrm{ab}}$ & $47.37^{\mathrm{a}}$ & 2.73 & 0.006 \\
\hline Aspartate aminotransferase, U/L & 30.24 & 34.27 & 29.57 & 3.18 & 0.608 \\
\hline Alkaline phosphatase, U/L & $214.24^{\mathrm{ab}}$ & $199.27^{\mathrm{b}}$ & $237.57^{\mathrm{a}}$ & 9.20 & 0.029 \\
\hline Immunoglobulin G, g/L & $1.36^{\mathrm{b}}$ & $1.76^{\mathrm{ab}}$ & $1.97^{\mathrm{a}}$ & 0.15 & 0.036 \\
\hline Immunoglobulin $\mathrm{M}, \mathrm{g} / \mathrm{L}$ & 0.36 & 0.45 & 0.48 & 0.04 & 0.121 \\
\hline \multicolumn{6}{|l|}{ Day 35} \\
\hline Total protein, g/L & $45.26^{\mathrm{b}}$ & $49.67^{\mathrm{ab}}$ & $52.98^{\mathrm{a}}$ & 1.95 & 0.046 \\
\hline Albumin, $\mathrm{g} / \mathrm{L}$ & 28.56 & 29.79 & 32.97 & 3.21 & 0.631 \\
\hline Blood urea nitrogen, $\mathrm{mmol} / \mathrm{L}$ & 4.39 & 4.06 & 3.78 & 0.18 & 0.083 \\
\hline Glucose, mmol/L & 6.87 & 6.79 & 6.94 & 0.16 & 0.838 \\
\hline Alanine transaminase, U/L & 35.19 & 39.46 & 41.38 & 2.81 & 0.306 \\
\hline Aspartate aminotransferase, U/L & 28.49 & 31.05 & 29.87 & 1.84 & 0.642 \\
\hline Alkaline phosphatase, U/L & 197.56 & 214.56 & 227.69 & 9.33 & 0.104 \\
\hline Immunoglobulin G, g/L & 1.27 & 1.58 & 1.87 & 0.18 & 0.088 \\
\hline Immunoglobulin $\mathrm{M}, \mathrm{g} / \mathrm{L}$ & 0.29 & 0.32 & 0.28 & 0.03 & 0.710 \\
\hline
\end{tabular}

$\mathrm{NC}=$ negative control, low-protein basal diet no antibiotics included; PC =positive control, low-protein Basal diet + antibiotics $(75$ ppm quinocetone, 20 ppm virginomycin and 50 ppm aureomycin); EUF = Eucommia ulmoides flavones, low-protein Basal diet $+0.1 \%$ EUF. Values are the mean \pm SEM, $\mathrm{n}=8$ per treatment group. ${ }^{\mathrm{a}-\mathrm{b}}$ Mean values sharing different superscripts within a row differ $(p<0.05)$. 


\begin{tabular}{|c|c|c|c|c|c|c|}
\hline $\log _{10} \mathrm{cfu} / \mathrm{g}$ & & NC & $\mathrm{PC}$ & EUF & SEM & $p$-value \\
\hline \multicolumn{7}{|l|}{ day 15} \\
\hline \multirow[t]{2}{*}{ Lactic acid bacteria } & ileum & $6.59^{\mathrm{b}}$ & $7.35^{\mathrm{ab}}$ & $7.49^{\mathrm{a}}$ & 0.13 & $<0.001$ \\
\hline & colon & 7.28 & 7.18 & 7.29 & 0.21 & 0.933 \\
\hline \multirow[t]{2}{*}{ Coliform bacteria } & ileum & $5.59^{a}$ & $4.58^{\mathrm{b}}$ & $4.76^{\mathrm{b}}$ & 0.19 & 0.003 \\
\hline & colon & 4.54 & 4.28 & 4.32 & 0.22 & 0.687 \\
\hline \multicolumn{7}{|l|}{ day 35} \\
\hline \multirow[t]{2}{*}{ Lactic acid bacteria } & ileum & 6.27 & 5.98 & 6.18 & 0.12 & 0.240 \\
\hline & colon & 7.15 & 6.87 & 7.09 & 0.25 & 0.721 \\
\hline \multirow[t]{2}{*}{ Coliform bacteria } & ileum & $4.79^{\mathrm{a}}$ & $4.15^{\mathrm{b}}$ & $4.06^{\mathrm{b}}$ & 0.15 & 0.001 \\
\hline & colon & 4.35 & 4.28 & 4.21 & 0.13 & 0.751 \\
\hline
\end{tabular}

$\mathrm{NC}=$ negative control, low-protein basal diet no antibiotics included; PC =positive control, low-protein Basal diet + antibiotics $(75$ ppm quinocetone, 20 ppm virginomycin and 50 ppm aureomycin); EUF = Eucommia ulmoides flavones, low-protein Basal diet + 0.1\%o EUF.Values are the mean \pm SEM, $\mathrm{n}=8$ per treatment group. ${ }^{\mathrm{a}-\mathrm{b}}$ Mean values sharing different superscripts within a row differ $(p<0.05)$

Table 4. Jejunal and Ileal Morphology in Piglets ${ }^{\mathrm{a}}$

\begin{tabular}{|c|c|c|c|c|c|c|}
\hline item & & NC & PC & EUF & SEM & $p$-value \\
\hline \multicolumn{7}{|l|}{ day 15} \\
\hline \multirow[t]{2}{*}{ villous height, $\mu \mathrm{m}$} & jejunum & $246.47^{b}$ & $274.32^{\mathrm{a}}$ & $276.35^{\mathrm{a}}$ & 7.80 & 0.023 \\
\hline & ileum & $197.89^{b}$ & $241.32^{\mathrm{a}}$ & $242.86^{\mathrm{a}}$ & 12.79 & 0.035 \\
\hline \multirow[t]{2}{*}{ crypt depth, $\mu \mathrm{m}$} & jejunum & 105.62 & 89.57 & 102.45 & 7.85 & 0.348 \\
\hline & ileum & 86.57 & 74.54 & 78.54 & 7.22 & 0.551 \\
\hline \multicolumn{7}{|l|}{ day 35} \\
\hline \multirow[t]{2}{*}{ villous height, $\mu \mathrm{m}$} & jejunum & 197.23 & 226.89 & 234.35 & 12.37 & 0.151 \\
\hline & ileum & 168.54 & 187.43 & 198.48 & 14.91 & 0.362 \\
\hline \multirow[t]{2}{*}{ crypt depth, $\mu \mathrm{m}$} & jejunum & 112.54 & 105.84 & 104.58 & 7.94 & 0.777 \\
\hline & ileum & 98.57 & 99.45 & 97.58 & 4.13 & 0.951 \\
\hline
\end{tabular}


$\mathrm{NC}=$ negative control, low-protein basal diet no antibiotics included; PC $=$ positive control, low-protein Basal diet + antibiotics $(75$ ppm quinocetone, 20 ppm virginomycin and 50 ppm aureomycin); EUF = Eucommia ulmoides flavones, low-protein Basal diet $+0.1 \%$ EUF. Values are the mean \pm SEM, $\mathrm{n}=8$ per treatment group. ${ }^{\mathrm{a}-\mathrm{b}}$ Mean values sharing different superscripts within a row differ $(p<0.05)$.

\section{Figures}
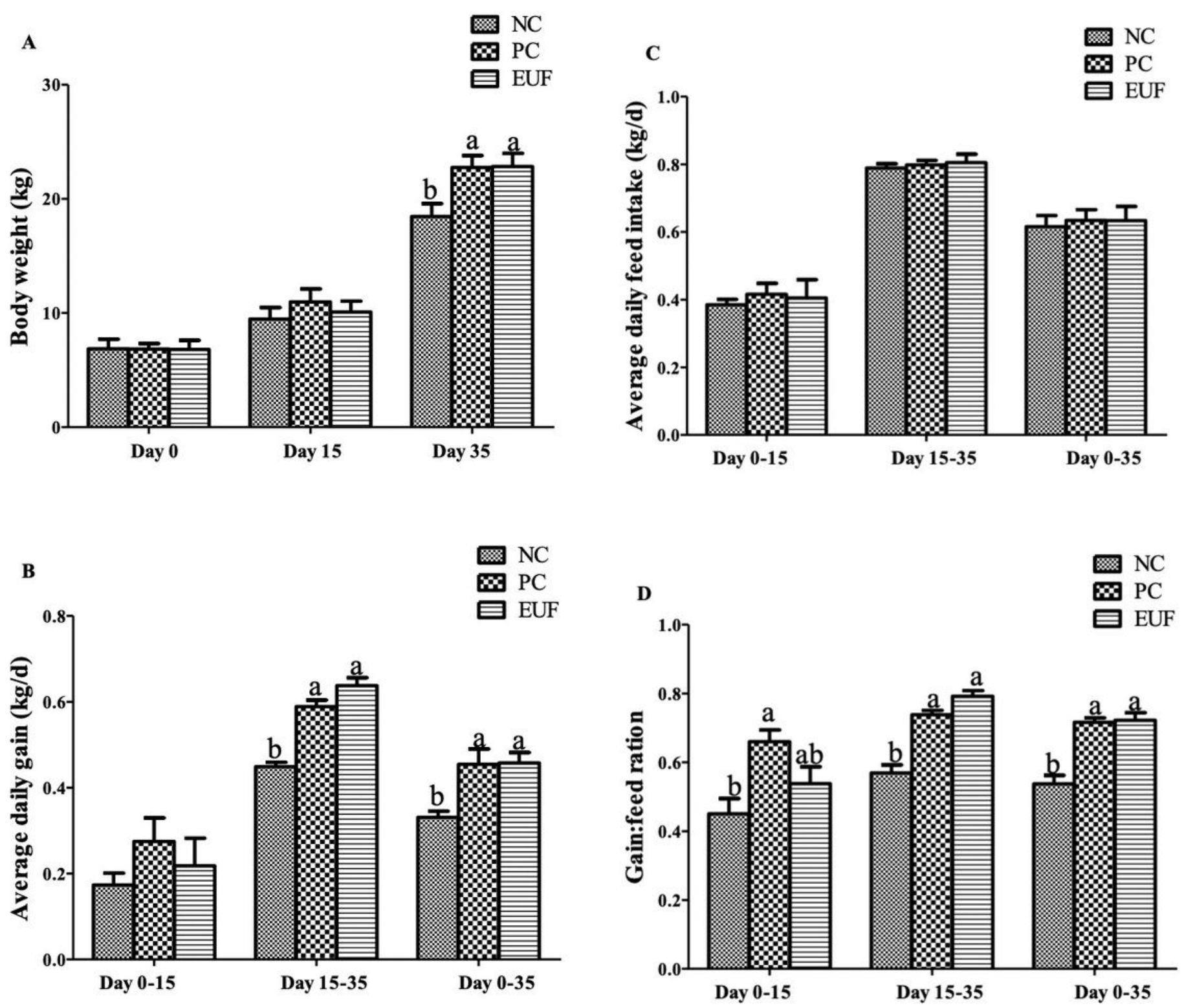

Figure 1

Growth Performance. A, body weight; B, average daily gain; C, average daily feed intake; D, Gain Z: feed ration; $\mathrm{NC}=$ negative control, low-protein basal diet no antibiotics included; $\mathrm{PC}=$ positive control, lowprotein Basal diet + antibiotics (75 ppm quinocetone, 20 ppm virginomycin and 50 ppm aureomycin); EUF 
$=$ Eucommia ulmoides flavones, low-protein Basal diet $+0.1 \%$ EUF. Values are the mean \pm SEM, $n=8$ per treatment group. a-bValues with different letters are significantly different $(p<0.05)$.

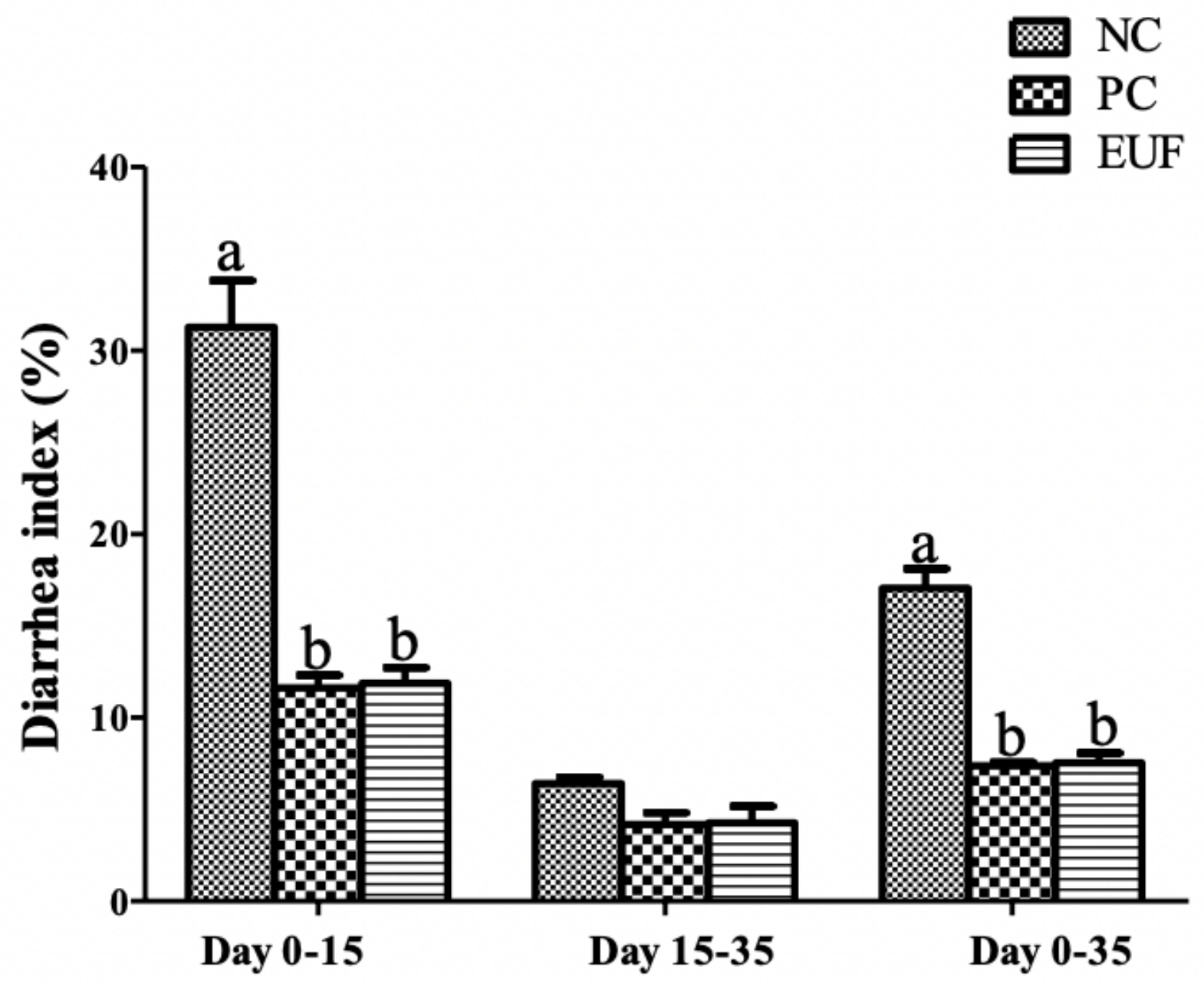

Figure 2

Diarrhea Index. NC = negative control, low-protein basal diet no antibiotics included; $P C=$ positive control, low-protein Basal diet + antibiotics (75 ppm quinocetone, 20 ppm virginomycin and 50 ppm aureomycin); EUF $=$ Eucommia ulmoides flavones, low-protein Basal diet $+0.1 \%$ oUF. Values are the mean $\pm S E M, n=$ 8 per treatment group. a-bValues with different letters are significantly different $(p<0.05)$. 

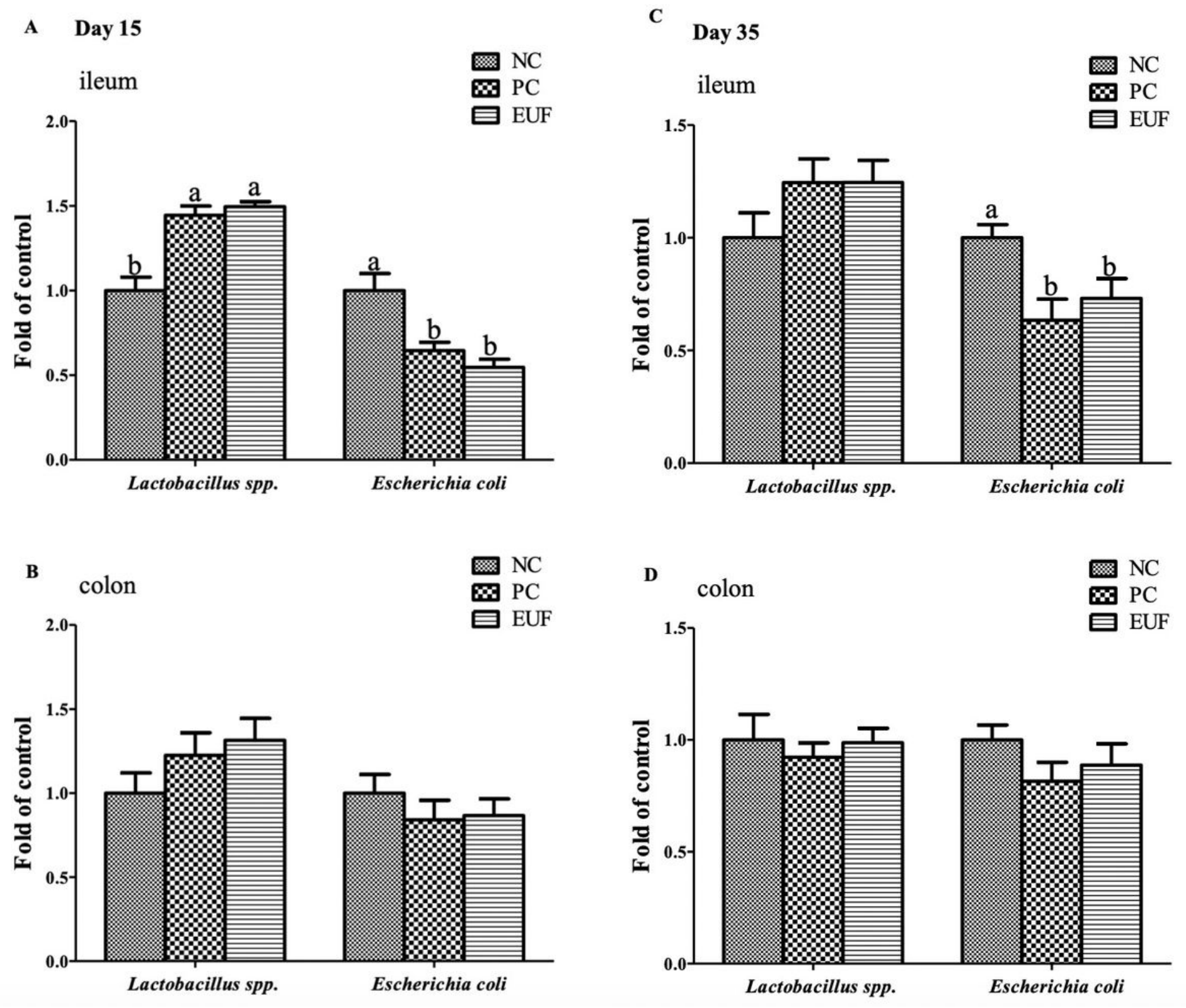

Figure 3

Relative abundance of Lactobacillus spp.and Escherichia coliin the ileum (A, B) and colon (C, D) of piglets. $\mathrm{NC}=$ negative control, low-protein basal diet no antibiotics included; PC =positive control, lowprotein Basal diet + antibiotics (75 ppm quinocetone, $20 \mathrm{ppm}$ virginomycin and $50 \mathrm{ppm}$ aureomycin); EUF $=$ Eucommia ulmoides flavones, low-protein Basal diet $+0.1 \%$ EUF. Values are the mean \pm SEM, $n=8$ per treatment group. a-bValues with different letters are significantly different $(p<0.05)$. 